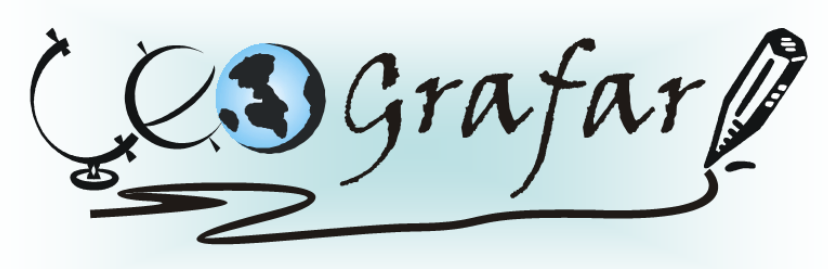

Revista Eletrônica do Programa de Pós-Graduação em Geografia - UFPR

\title{
OS PROGRAMAS DE CRÉDITOS PARA OS ASSENTAMENTOS RURAIS - O ESTUDO DE CASO DO DORCELINA FOLADOR (ARAPONGAS - PR.)
}

\author{
PAULA CHAGAS FRANCIS ${ }^{1}$
}

\begin{abstract}
Resumo: As políticas públicas adotadas pelo governo em prol de um desenvolvimento para o campo brasileiro têm beneficiado agricultores familiares de forma dispare, a exemplo dos financiamentos agrícolas. Criados com a finalidade de fornecer recursos públicos aos agricultores familiares, os créditos rurais foram considerados em seu passado uma das políticas públicas mais perversas até então adotadas. No entanto, seguindo as mesmas características novas políticas continuam vigorando pelo campo ocasionando um conjunto de discrepâncias sociais e econômicas entre agricultores familiares. A fim de estabelecer um comparativo, o presente artigo tem como foco de analise dois programas: o PROCERA, criado para atender particularmente aos assentados rurais, bloqueado pelo governo de Fernando Henrique Cardoso (1995- 2002); e o PRONAF, desenvolvido no ano de 1995 como uma estratégia de fortalecimento da agricultura familiar. Assentados rurais, pertencentes ao Movimento dos Trabalhadores Rurais Sem Terra (MST), mesmo contrários às medidas adotadas pelo governo desde o período da Revolução Verde, tem tido acesso aos financiamentos agrícolas, possibilitando que desenvolvam suas lavouras e invistam em seus lotes de terra. Os resultados que focam este artigo, referem-se ao Assentamento Rural Dorcelina Folador, localizado no município de Arapongas (PR.), que se destaca dos demais por seu fácil acesso e por suas particularidades adotadas desde sua criação.
\end{abstract}

Palavras-chave: Políticas públicas; assentados rurais; PROCERA; PRONAF.

\section{THE CREDIT PROGRAMS FOR RURAL SETTLEMENTS: THE CASE STUDY OF DORCELINA FOLADOR (ARAPONGAS - PR)}

\begin{abstract}
The public policies adopted by the Government towards a development for the Brazilian agrarian spaces have been providing benefits for family farmers unevenly and the farming financing are an example of this reality. These financing funds were created in order to provide public resources to family farmers and they were considered one of the most harmful policies that were ever employed. This work aims to establish a comparison through an analysis of two programs: PROCERA, that had been originally created to serve peasants with lots associated to social movements such as the MST. It was blocked by the former president Fernando Henrique Cardoso (1995-2002). The other program is PRONAF, that was developed in 1995 as a strategy for strengthening family farmers. Rural peasants that are associated to the Movimento dos Trabalhadores Rurais Sem Terra (MST), even opposed to the governmental measures since the Green Revolution period, have been granted the access to these funds that enable the growth of crops and investments on their land lots. The results that guide this article are related to the MST settlement of Dorcelina Folador, located in Arapontas-PR, which is a privileged town due to its easy access and the particularities adopted since it was founded.
\end{abstract}

Key-words: Public Policies; Rural lots peasants; PROCERA; PRONAF

\footnotetext{
${ }^{1}$ Aluna regular do Curso de Pós-Graduação Mestrado e Doutorado em Geografia da Universidade Federal do Paraná (UFPR)
} 


\section{INTRODUÇÃO}

Os assentamentos rurais presentes pelo campo brasileiro usufruem direitos por parte do governo, no que diz respeito ao acesso aos financiamentos agrícolas. O primeiro programa desenvolvido para atender de forma prioritária aos assentados rurais foi o já extinto PROCERA, no entanto o mesmo fora bloqueado pelo governo de Fernando Henrique Cardoso, dando início a um período de confronto entre governo e MST.

Como solução dada, assentados rurais foram incorporados ao universo dos agricultores familiares, tendo acesso a dois grupos do programa PRONAF, os grupos "A" e "A/C", proporcionando-lhes os meios necessários para investirem em suas propriedades e desenvolverem suas lavouras.

A necessidade de políticas públicas que sejam articuladas para atender aos agricultores familiares é um fato, envolvem atuações dos governos federais, estaduais e municipais; porém as metas adotadas desde o período da Revolução Verde têm dado prioridade tão somente a agricultores familiares com alto grau de integração com os setores agroindustriais, deixando o restante à margem.

Considerado um assentamento rural a partir do ano de 1999 o Dorcelina Folador, localizado nas proximidades do município de Arapongas (Paraná) comporta assentados rurais que já acessaram aos dois programas, o que permite uma análise comparativa.

Este artigo traz informações que possibilitam extrair o grau de satisfação dos assentados em relação a cada programa. As informações coletadas referem-se à aplicação de questionários in loco nas datas de 10/10/05 e 11/10/05, a um número de 20 assentados em forma de entrevista pessoal, com caráter qualitativo; visto já existirem 81 questionários aplicados pelo grupo PET/Geografia da Universidade Estadual de Londrina (UEL).

\section{AS POLÍTICAS PÚBLICAS BRASILEIRAS}

$\mathrm{Na}$ atualidade inúmeros agricultores familiares têm dificuldades no desenvolvimento de suas lavouras, atrelado a isto desde anos o campo brasileiro vem se deparando com políticas públicas que não lhes tem proporcionado ganhos satisfatórios em suas produções. 
Negri (2005) menciona a existência de um "capitalismo selvagem", que se encontra instalado principalmente no campo, mediante políticas públicas sempre favoráveis a uma minoria; os grandes proprietários, deixando à margem o restante da população.

Fruto da abertura política ao capital estrangeiro, em que produtos destinados à exportação recebiam os maiores subsídios, as décadas de 1960 a 1970 foram marcadas pela modernização agrícola; indústrias oriundas do exterior foram instaladas pelo território brasileiro, no entanto era necessária a existência de um mercado consumidor para os novos meios de produção que estavam sendo criados tais como: insumos, fertilizantes e maquinários.

Foi neste momento que o governo forneceu incentivos fiscais para a aquisição destes novos aparatos tecnológicos; sendo assim, os créditos rurais foram desenvolvidos para fornecer recursos públicos aos agricultores familiares. Porém, foi considerada uma das políticas públicas mais perversas do momento e altamente seletivas, uma vez que apenas médios e grandes produtores foram beneficiados por crédito farto e barato para investirem em suas propriedades (HESPANHOL, 2007).

Visto a dificuldade de dispor de capital para adquirir estas novas tecnologias agricultores familiares sem condições econômicas de concorrem com o que eram produzidos pelas indústrias tiveram de optar por outros tipos de produções. Diversos agricultores familiares com o intuito de elevarem suas rendas recorreram a outras formas de empregos, nas lavouras vizinhas ou até mesmo em cidades próximas.

O Movimento dos Trabalhadores Rurais Sem Terra (MST), até os dias de hoje, possui uma posição contrária às políticas públicas adotadas pelo governo desde a Revolução Verde, as quais eram voltadas tão somente à mecanização da agricultura reduzindo ao máximo o uso de mão-de-obra, gerando uma concentração cada vez maior do capital nas mãos de uma minoria, ou seja, uma busca incessante pelo o aumento da produtividade e maior concentração de terras (NEGRI, 2005).

Este movimento permanece pelo campo reivindicando por inúmeros direitos, por exemplo, uma reforma agrária diferente da proposta até o momento, com uma melhor distribuição de terras pelo território brasileiro. Além disto, a luta pelo acesso a terra é apenas o primeiro passo, pois nela se incluem as lutas contra as políticas públicas e as formas de tratamento dispensadas pelo Estado. 
No início da reforma agrária brasileira várias críticas eram feitas ao pequeno apoio dado aos assentados rurais, tanto com relação aos recursos financeiros, bem como em termos de assistência técnica, extensão rural e demais serviços públicos (GUANZIROLI el al. 2001, p. 229).

Ao passo em que estes serviços sejam atendidos o campo brasileiro tenderá a se desenvolver de forma mais satisfatória, permitindo que assentados rurais tenham condições econômicas e sociais favoráveis a sua inserção e manutenção no campo.

Em contrapartida, o Estado em prol do "desenvolvimento" tem proposto políticas públicas voltadas para grandes complexos agroindustriais, que visam tão somente ao abastecimento do mercado interno e ao aumento das exportações. Dentre as diversas medidas adotadas pelo Estado a oferta dos créditos rurais delineiam a realidade pela qual o campo perpassa.

\section{O SISTEMA NACIONAL DE CRÉDITO RURAL (SNCR)}

$\mathrm{Na}$ tentativa de levar o desenvolvimento ao campo o governo gera mudanças econômicas e sociais através do exercício de seu poder. Poder este que vem sendo posto em prática desde anos, por exemplo, com a adoção do Sistema Nacional de Crédito Rural (SNRC), criado no ano de 1965. Este desenvolvimento "não consegue se desassociar das palavras com as quais foi criado: crescimento, evolução, maturação" (ESTEVA, 2000, p. 64).

No entanto, mesmo com a finalidade de facilitar o acesso dos agricultores familiares aos recursos públicos, e vindo com o propósito de beneficiar aos agricultores menos capitalizados, desenvolvimento e crescimento econômico não vem ocorrendo de fato.

O Sistema Nacional de Crédito Rural (SNCR) em sua legislação tinha por meta incentivar a produção agrícola e, ao mesmo tempo proteger pequenos produtores rurais, promovendo concomitantemente a modernização da agricultura. Para Francis (2005, p. 34) "proteger pequenos agricultores e ao mesmo tempo promover a modernização é algo de difícil compreensão", visto que apenas parte de proprietários se beneficiou desta, sendo por tanto uma dualidade. 
Foram dados grandes incentivos fiscais tanto para a comercialização bem como para o custeio da produção de agricultores familiares, porém privilegiaram-se apenas os que possuíam alto grau de integração com os setores agroindústrias, deixando o restante à margem, uma agricultura realizada tão somente em bases técnicas modernas (HESPANHOL, 2007, p. 274).

Atrelado a isto foram viabilizadas vendas de maquinários para a população do campo a um preço irrisório permitindo assim a sua mecanização. Entretanto, em decorrência da crise fiscal do Estado brasileiro, somado ao fato dos créditos rurais serem fartos, subsidiados a baixas taxas de juros e de fácil acesso, estes acabaram por se esgotar.

Seguindo as mesmas características dos SNCR, anterior à medida adotada pelo governo de incorporar assentados rurais ao universo dos agricultores familiares, havia um crédito que atendia de forma específica aos assentados rurais, denominado por Programa de Crédito Especial para a Reforma Agrária (PROCERA). O Dorcelina Folador permite uma análise deste programa, uma vez que seus assentados tiveram acesso ao mesmo.

\section{O ASSENTAMENTO RURAL DORCELINA FOLADOR}

Localizado na Região Norte do Paraná nas proximidades do município de Arapongas (PR), o assentamento rural ocupa uma área de 775 hectares. Em 1999 seus lotes foram demarcados por técnico do Instituto Nacional de Colonização e Reforma Agrária (INCRA), sendo distribuídos de forma igualitária pelo movimento; para se tornar assentado todos os interessados passaram por uma seleção (FRANCIS, 2005, p. 64).

Em sua instalação havia a presença de 10 núcleos em torno de 8 a 12 famílias cada, os quais possuíam as seguintes denominações: Renascer, Florestan Fernandes, Frutos da Terra, Roseli Nunes, Osiel, Arajú, Nova União, Nossa Terra, Cepet e Antônio Conselheiro (FRANCIS, 2005).

Em seu início era intuito assentar um total de 64 famílias para possibilitar o acesso a lotes maiores; porém, como na época muitas famílias estavam sendo assentadas e existiam vários projetos para assentamentos, o local passou a comportar 94 famílias, diminuindo assim o tamanho dos lotes (cerca de seis hectares). 


\title{
O PROCERA NO DORCELINA FOLADOR
}

A partir do momento em que assentados rurais tomam posse de seus lotes passam a ter acesso a vários direitos, dentre estes se inclui os créditos rurais, para a obtenção de maquinários, insumos agrícolas e à instalação de infra-estrutura de produção. $\mathrm{O}$ primeiro crédito fornecido aos assentados foi o PROCERA, que adotou quase que em sua totalidade todas as características dos programas especiais dos créditos rurais.

O PROCERA funcionou entre o período de 1986 a 1999, segundo dados de seu Relatório de Gestão vinha com o objetivo de:

\begin{abstract}
Aumentar a produção e a produtividade agrícolas dos assentados da reforma agrária, com sua plena inserção no mercado, mediante financiamento de projetos para estruturação da capacidade produtiva e aproveitamento econômico das áreas de assentamento aprovadas pelo Instituto Nacional de Colonização e Reforma Agrária - INCRA, visando permitir a devida emancipação do produtor em relação a tutela governamental (BRASIL. RELATÓRIO DE GESTÃO - PROCERA Brasília: 2003, p. 05).
\end{abstract}

De acordo com o relatório durante este período vários valores foram definidos para o teto do financiamento, na última versão editada em 1997 das normas de administração gerais do programa, observavam-se as seguintes condições:

- teto para investimentos com o valor de $R \$ 7.500 .00$ por família, e para custeio de lavoura $R \$ 2.000 .00$ por família/ano;

- no caso de financiamento para integralização de quotas-partes do capital social de cooperativas de assentados, a família tinha direito a mais outro teto de $R \$ 7.500 .00$ a título de investimento;

- os encargos financeiros eram de 6.5\% ao ano, com rebate de 50\% sobre as parcelas de amortização do principal e juros, no caso do pagamento ocorrer até a data do vencimento;

- as prestações podiam ser pagas semestralmente ou anualmente, conforme o bem financiado, com prazo de até 10 anos, com 03 anos de carência; 
- as garantias exigidas eram: para os investimentos concedidos, o aval prestado por outro produtor assentado, independente de sua capacidade financeira e para o custeio de lavouras, o penhor da safra ou aval de outro produtor assentado.

Ao Banco do Brasil era papel cumprir determinadas medidas, as quais foram definidas pelo relatório como sendo:

- Elaborar a ficha cadastral dos proponentes ao crédito;

- Acolher os projetos e propostas de crédito aprovadas pela Comissão Estadual do PROCERA;

- Contratar os financiamentos com os beneficiários;

- Fiscalizar as operações de crédito;

- Articular-se com a Assistência Técnica, objetivando o eficiente desempenho junto à Reforma Agrária;

- Fornecer aos órgãos de coordenação do PROCERA as informações necessárias ao acompanhamento e avaliação;

- Efetuar as cobranças das dívidas, recolhendo ao Fundo Contábil os valores recebidos;

- Tomar medidas necessárias à recuperação do crédito concedido, em caso de inadimplemento;

- Após a criação dos Fundos Constitucionais, em 1993, estes passaram a ser operacionalizados pelos Agentes Financeiros: Banco da Amazônia (FNO), Banco do Nordeste (FNE) e Banco do Brasil (FCO).

Porém, Banco do Brasil deveria estar articulado com a assistência técnica que deveria:

- Avaliar a área objeto do assentamento, visando determinar as melhores alternativas de exploração produtiva;

- Formular projetos de desenvolvimento econômico das áreas objeto de assentamentos, os encaminhado às Comissões Estaduais para análise;

- Prestar orientação técnico-gerencial às famílias, associações e cooperativas de produtores assentados; 
- Avaliar os investimentos executados;

- Elaborar relatórios relativos à assistência técnica prestada nos assentamentos;

- Apresentar Plano Anual de Assistência Técnica.

No entanto de acordo com o relatório o PROCERA não alcançou o objetivo principal para o qual fora criado, o de propiciar a emancipação do assentado em relação ao Estado. Tanto com relação ao proposto pelas agências bancárias bem como pela assistência técnica, eram itens difíceis de serem alcançados, visto a abrangência das medidas.

Segundo dados do relatório diversos foram os fatores que contribuíram para a extinção do programa, destacando-se:

- A falta de uma política pública consistente para a reforma agrária;

- A situação precária e decadente da Assistência Técnica disponível que passou por um processo de desmontagem durante anos;

- Má distribuição, descontinuidade e volume insuficiente de recursos para atender a demanda;

- Sistema bancário conservador e despreparado para atender ao produtor assentado.

No que diz respeito aos valores estipulados para o PROCERA este se subdividia em crédito para implantação (alimentação, fomento e habitação) e crédito para produção (PROCERA: custeio, PROCERA: Teto I e PROCERA: Teto II).

Proscêncio (1999) esclarece os valores que eram ofertados por cada crédito, os quais eram respectivamente:

a) Crédito para implantação:

Alimentação R\$ 400.00

Fomento R $\$ 740.00$

Habitação R \$ 2.000.00

b) Crédito para produção:

PROCERA: custeio R $\$ 2.000 .00$

PROCERA: Teto I R \$ 7.500.00

PROCERA: Teto II 
Segundo a autora, o crédito de alimentação era feito sob diversas formas: salário mínimo durante os 10 primeiros meses para cada família; sendo que o valor também podia ser fornecido via alimentos; ou mesmo mediante a realização de convênio com cooperativas para barateamento dos produtos. Além disto, era possível liberar o valor total em dinheiro de uma só vez.

Com relação ao crédito de fomento equivalia ao recurso com o qual cada família contava para adquirir suas primeiras ferramentas, sementes e animais. Já o crédito de habitação era fornecido para a construção da casa, cabendo ao assentado comprar os materiais necessários.

Os créditos para a produção como o PROCERA Custeio correspondia ao valor para realizar a lavoura do ano, tendo como prazo de pagamento o período de um ano. Já o recurso do Teto I era fornecido para o investimento da propriedade adquirindo animais e ferramentas, por exemplo.

Salienta-se que o recurso do Teto I era diferente do fomento, pois o último era fornecido aos assentados em sua fase de implantação no local. Com relação ao Teto II, um crédito a mais do PROCERA, destinava-se às famílias assentadas, sócias de cooperativas.

No entanto os créditos de alimentação, fomento e habitação por não serem créditos produtivos, acabavam às vezes sendo considerados pelos assentados como uma "doação" do Estado, gerando problemas de inadimplência. Em diversos casos, mesmo nos dias de hoje, há uma nítida dificuldade em distinguir um crédito do outro devido à falta de informação. Estes créditos deveriam ser considerados como fundo perdido visto se tratar de dotar famílias de um mínimo de condições humanitárias necessárias à sua inserção social, econômica e produtiva (LEITE et al., 2004).

No Assentamento Rural Dorcelina Folador houve a problemática da liberação destes créditos, como bem enfatizado por Leite et al. (2004), muitas vezes é uma das principais dificuldades pelas quais os assentados se deparam; esta normalmente ocorre após o período do plantio, comprometendo significativamente a produção agropecuária.

Fora isto ainda há a problemática da modalidade para habitação, a qual sempre demora a ser liberada, tornando ainda mais penosa a fase inicial do assentado. Além do mais, este 
somente terá seus primeiros rendimentos com sua primeira colheita. Segundo Francis (2005), no assentamento rural vários foram os assentados que tiveram de utilizar recursos próprios para finalizarem suas casas.

Até o período da aplicação dos questionários in loco havia assentados que não tinham terminado suas casas, residindo nelas mesmo assim, pois como exposto na fala de um deles: "Não deu nem para a mão-de-obra. O que tenho hoje foi com recurso próprio da lavoura". Já outra família mencionou: "Parou nisso aqui que cê tá vendo! $42 \mathrm{~m}^{2}$ é muito pouco" (FRANCIS, 2005, p 101).

Apenas famílias que no período trabalhavam com a criação do bicho-da-seda em seus lotes, foram as que conseguiram terminar a construção das casas. Uma das entrevistadas afirmou finalizar a construção num período bem posterior, conseguindo ampliá-la com recurso próprio via criação do bicho-da-seda.

O que se constata é que a maioria dos beneficiários da reforma agrária assume o lote em condições de completa descapitalização, sem meios próprios para desenvolver sua lavoura inicial. De fato, o atraso na liberação do recurso ocorreu no próprio Dorcelina Folador, uma vez que as exigências burocráticas do programa atrasaram ainda mais a liberação. Desta forma, desde a fase inicial os assentados tiveram acesso a alguns auxílios:

\begin{tabular}{ccc}
\multicolumn{3}{c}{ 1- TABELA AUXÍLIOS FORNECIDOS AOS ASSENTADOS } \\
\hline AUXÍLIOS & N. $^{\mathbf{0}}$ de FAMÍLIAS & $\mathbf{\%}$ \\
\hline Amigos e parentes & 4 & 4.9 \\
MST & 8 & 9.9 \\
PROCERA & 38 & 46.9 \\
Nenhum auxílio & 23 & 28.4 \\
CPT & 2 & 2.5 \\
Não soube responder & 6 & 7.4 \\
\hline TOTAL & $\mathbf{8 1}$ & $\mathbf{1 0 0}$ \\
\hline
\end{tabular}

Fonte: Pesquisa in loco Dorcelina Folador (Arapongas - PR).

Data: $26 / 08 / 04$

Uma porcentagem considerável dos assentados teve acesso ao PROCERA (46.9\%), possibilitando-os de adquirir os recursos referentes a: investimento, fomento e habitação, que perfaziam um total na época de $\mathrm{R} \$ 12.000 .00$ (doze mil reais). O percentual de $28.4 \%$ que não recebeu nenhum auxílio é interpretado como fazendo referência às famílias que chegaram num período posterior ao local. 
Sobre a obtenção dos primeiros créditos Guanziroli et al. (2001, p. 215) enfatizam que a maior parte dos assentamentos da região Sul é originária de ocupações realizadas pelo MST, e no caso desta região as primeiras famílias passaram por inúmeras dificuldades devido à demora na liberação destes créditos, várias abandonaram a área, por não terem condições de resistir por muito tempo.

\section{2- TABELA DIFICULDADES ENFRENTADAS AO CHEGAR NO LOCAL}

\begin{tabular}{|c|c|c|}
\hline $\begin{array}{r}\text { DIFICULDADES } \\
\end{array}$ & N. ${ }^{\circ}$ de FAMÍLIAS & $\%$ \\
\hline Falta de recursos financeiros & 36 & 44.3 \\
\hline Falta de infra-estrutura & 10 & 12.2 \\
\hline Preconceito & 9 & 10.4 \\
\hline Não especificaram & 6 & 7.8 \\
\hline Falta de trabalho & 5 & 6.9 \\
\hline Nenhuma & 4 & 6.1 \\
\hline Comercialização & 3 & 3.5 \\
\hline Falta de demarcação & 3 & 3.5 \\
\hline Trauma de despejo & 2 & 2.6 \\
\hline Burocracia & 1 & 0.9 \\
\hline Dívidas no banco & 1 & 0.9 \\
\hline Geada & 1 & 0.9 \\
\hline
\end{tabular}

Fonte: Pesquisa in loco Dorcelina Folador (Arapongas - PR.).

Data: 26/08/04.

Pelas entrevistas realizadas no ano de 2004 a maioria das famílias não possuía bens ao chegarem ao local, “... cheguei sem nada, o que eu tenho hoje, tô rico!"; comprovando-se que, no geral, estas assumem o lote em condições de completa descapitalização. (FRANCIS, 2005, p. 97).

Diversas foram as dificuldades, sendo que a falta de recursos financeiros foi a mais citada (44.3\%). Neste percentual incluem-se a falta de recurso para realizar a lavoura, de uma moradia adequada, de alimentos e água para sobreviverem.

Além disto, assentados mencionaram a necessidade de realizarem trabalhos diários para fazendeiros, visto ser a única forma de se manter na fase inicial. 12.2\% afirmaram que no início não possuíam uma infra-estrutura adequada, "como a existência de: transportes, escolas, bem como a falta de energia elétrica no interior do assentamento" (FRANCIS, 2005, p. 96). 
Segundo a autora estas dificuldades devem ser consideradas, pois perpassam desde a obtenção de uma boa produtividade até a falta de recursos, atrelado a isto ainda há os gastos elevados com insumos e maquinários. A fase inicial foi realmente problemática, no entanto:

\begin{abstract}
A mais penosa foi a demora da liberação dos recursos para habitação, tendo que improvisá-la, construindo barracos ou utilizando as antigas casas da sede da propriedade. Uma das famílias expôs que “... no começo foi tudo difícil, principalmente para construir a casa”. (FRANCIS, 2005, p. 96).
\end{abstract}

Em sua maioria das famílias que chegaram ao assentamento com algum bem tiveram de vendê-lo antes de obter seus primeiros rendimentos em suas colheitas. Convêm citar que um dos maiores problemas diz respeito ao primeiro ano em que o assentado se instala no lote, uma vez que este depende da primeira colheita para extrair sua renda inicial.

Outro fator relevante é a dificuldade dos assentados distinguirem os diferentes tipos de créditos que lhes foram ofertados neste período; sendo assim, questionar até que ponto receberam as informações necessárias para o uso adequado do financiamento, a fim de obter uma boa produtividade, precisa ser levado em conta. Quando indagados sobre os valores recebidos para cada modalidade um casal entrou em controvérsia, onde a esposa dizia "... não, esse que era para habitação".

\title{
DO PROCERA AO PRONAF
}

Foi no governo de Fernando Henrique Cardoso (1995- 2002) que o PROCERA fora bloqueado, dando início a um período de complicadas negociações; em que o presidente se viu obrigado a negociar com esta parcela da população para amenizar a problemática dos recursos ofertados aos assentados rurais.

Visto o bloqueio, em sua maioria, os assentados não tiveram continuidade ao crédito custeio, passando na safra posterior por diversas dificuldades, sem possibilidades de arcar com despesas como os gastos de aluguéis de maquinários, insumos, sementes, calcários, dentre outras. 
Como solução dada PRONAF (Programa Nacional de Fortalecimento da Agricultura Familiar) e PROCERA foram unificados, no entanto uma das críticas feitas ao programa PRONAF foi o fato deste unir um público tão grande e heterogêneo tratando-o como um só.

Ao incorporar assentados ao universo de agricultores familiares, ignorou-se na realidade o alto grau de diversidade presente no campo brasileiro entre os agricultores (ALENTEJANO, 2000), visto que ambos deveriam receber um tratamento diferenciado, porém este somente se distinguia nas variadas condições de pagamento da dívida contraída.

Por se sentirem cada vez mais marginalizados os movimentos sociais passaram por um período de confronto com o Estado, um longo e conturbado processo de negociações de créditos para assentados, que resultou na criação de linhas de créditos especiais para atendêlos, os atuais grupos "A" $\mathrm{e}$ "A/C" do programa.

Com relação ao Grupo A este permite o investimento para a estruturação inicial do lote, tendo como prazo de pagamento 10 anos. Já para desenvolverem a lavoura criou-se o Grupo A/C, que corresponde ao primeiro crédito de custeio dos agricultores que já tiveram acesso ao investimento do Grupo A, com prazo de pagamento de até dois anos, conforme a atividade financiada.

De acordo com a RESOLUÇÃO Nº 3.559 do Banco Central do Brasil estes grupos possuem as seguintes características:

Grupo A: agricultores familiares assentados pelo Programa Nacional de Reforma Agrária (PNRA) ou beneficiários do Programa Nacional de Crédito Fundiário (PNCF) que não foram contemplados com operação de investimento do PROCERA ou que ainda não foram contemplados com o limite do crédito de investimento do PRONAF;

Grupo A/C: agricultores familiares assentados pelo PNRA ou beneficiários do PNCF, que:

I - apresentem DAP para o Grupo "A/C", fornecida pelo Incra para os beneficiários do PNRA ou pela Unidade Técnica Estadual ou Regional (UTE/UTR) para os beneficiados pelo PNCF;

II - já tenham contratado a primeira operação no Grupo "A";

III - não tenham contraído financiamento de custeio, exceto no Grupo "A/C". 
Foram incorporados tanto os assentados pelo Instituto Nacional de Colonização e Reforma Agrária (INCRA), que não tinham ainda atingido os limites necessários fixados pela linha de crédito que lhes dava suporte, o antigo PROCERA, bem como os novos assentados (FERREIRA et al., 2001, p. 497).

No PRONAF envolvem-se atuações dos Governos Federal, Estadual e Municipal atendendo aos agricultores familiares; desenvolvido para fornecer recursos públicos aos agricultores familiares destituídos de elevada renda foi proposto com os objetivos de:

\begin{abstract}
Ajustar políticas públicas à realidade da agricultura familiar; viabilizar a infraestrutura rural necessária à melhoria do desempenho produtivo e da qualidade de vida da população rural; fortalecer o serviço de apoio ao desenvolvimento da agricultura familiar; elevar o nível de profissionalização de agricultores familiares, proporciando-lhes novos padrões tecnológicos e de gestão; favorecer o acesso de agricultores familiares e suas organizações ao mercado de produtos e insumos (Ministério do Desenvolvimento Agrário).
\end{abstract}

Em se tratando dos assentados do Dorcelina Folador estes tiveram acesso tanto ao PROCERA bem como ao PRONAF, como se pode observar:

\title{
3- TABELA CRÉDITOS RURAIS DESTINADOS AOS ASSENTADOS
}

\begin{tabular}{lcc}
\hline & N. $^{\mathbf{0}}$ de FAMÍLIAS & \% \\
\hline PROCERA & 34 & 42 \\
PROCERA e PRONAF A/C & 34 & 42 \\
Nenhuma ajuda & 7 & 8.6 \\
PRONAF A & 5 & 6.2 \\
Não soube responder & 1 & 1.2 \\
\hline \multicolumn{1}{c}{ TOTAL } & $\mathbf{8 1}$ & $\mathbf{1 0 0}$ \\
\hline
\end{tabular}

Fonte: Pesquisa in loco Dorcelina Folador (Arapongas - PR.).

Data: $26 / 08 / 04$

O recurso referente ao PROCERA possibilitou aos assentados de adquirirem seus meios de produção, sendo os mais citados "barracões, lona, paiol, telas, cercas, adubos, sementes, estercos, entre outros" (FRANCIS, 2005, p. 92). O percentual de $42 \%$ teve acesso ao PROCERA e ao PRONAF A/C, sendo este último destinado para o custeio da lavoura.

Em contrapartida, $8.6 \%$ dos assentados não tiveram acesso a nenhum auxílio do governo, pelo fato de possuírem dívidas com o Banco do Brasil, por exemplo. Por fim, 6.2\% tiveram acesso ao PRONAF A, comprovando-se que nem todas as famílias estavam no local desde o ano de implantação do assentamento. 
A tabela a seguir ilustra os assentados que solicitaram tanto o PRONAF A bem como o PRONAF A/C:

4- TABELA ASSENTADOS QUE SOLICITARAM PRONAF A OU PRONAF A/C

\begin{tabular}{lcc}
\hline & N.'de ASSENTADOS & \% \\
\hline Assentados contemplados com PRONAF A & 1 & 5 \\
Assentados contemplados com PRONAF A/C & 15 & 75 \\
Não realizaram financiamento & 4 & 20 \\
\hline \multicolumn{1}{c}{ TOTAL } & $\mathbf{2 0}$ & $\mathbf{1 0 0}$ \\
\hline
\end{tabular}

Fonte: Pesquisa in loco Dorcelina Folador (Arapongas - PR.).

Período: 10/10/05 e 11/10/05.

Dos assentados um total de $75 \%$, ou seja, a maioria teve acesso ao PRONAF A/C, para o custeio da lavoura, apenas um ao PRONAF A, referente ao investimento; neste caso em particular, o assentado não havia feito o PROCERA. No entanto, pela existência de dívidas com o banco, cerca de $20 \%$ não o fez.

Além dos objetivos propostos pelo programa o PRONAF permite que agricultores familiares acessem ao financiamento da produção, da capacitação e profissionalização. Para isto cabe ao agricultor buscar o serviço de assistência técnica, Sindicato ou Federação de Trabalhadores credenciados pelo programa, responsáveis pela emissão do certificado de aptidão declarando que o interessado cumpre os requisitos necessários. Porém, para o agricultor acessar determinado grupo é preciso que obtenha a renda mínima estipulada para cada grupo, dentre outras exigências impostas pelo programa.

É permitido ao assentado tentar nos anos seguintes se enquadrar em outro grupo que lhe oferte maior crédito, no entanto é necessária a comprovação da renda mediante a Declaração de Aptidão ao PRONAF (DAP) fornecida pela EMATER. Porém, a dificuldade de se enquadrar em outros grupos é uma realidade, visto as rendas exigidas, algo fora da realidade para o assentado rural.

Além da problemática de se enquadrarem em determinado grupo, Alentejano (2000, p. 91) enfatiza que o mercado é por si só seletivo, a idéia de mercado ignora as desigualdades presentes entre agricultores familiares, assim como a existência de intermediários (as agências bancárias) e a formação de preços pela agroindústria. 
A demora na liberação do PRONAF pelo Banco do Brasil, responsável pelo seu repasse, é um fato relevante, pois em vários casos são solicitadas a terra e a produção como garantias reais; além disto, nem sempre a época da liberação do financiamento é favorável aos agricultores (FRANCIS, 2005, p. 35).

Com relação à capacidade produtiva Leite et al. (2004) enfatizam que o acesso ao crédito além de repercutir no assentamento, também impulsiona as várias atividades locais do município aumentando a circulação monetária do respectivo, o que afeta a economia local. Entretanto:

[...] O fato de vários desses créditos serem liberados de uma só vez chega a provocar verdadeiros "alvoroços" no comércio local, com esgotamento de estoques de materiais (de construção, insumos agrícolas, matrizes de animais...) ocasionado "processos inflacionários" momentâneos e locais, que algumas vezes levam os assentados a pagarem preços mais elevados pelos produtos. (LEITE et al., 2004, p. 226)

O que se observa é que agências bancárias, como o Banco do Brasil, não fazem parte do universo de relações da maioria dos assentados rurais, uma vez que grande número não possui nenhum bem patrimonial e/ou renda suficiente para oferecer a estes garantias reais que evocam elevados custos.

É fato a insatisfação dos assentados do Dorcelina Folador frente ao PRONAF, um ponto negativo é o problema de estarem sempre endividados, tendo muitas vezes de renegociar suas dívidas para acessar ao financiamento seguinte; além disto, mesmo pagando parte da dívida o assentado continua devendo ao banco.

Há a preocupação em quitarem suas dívidas, visto ser o único recurso que dispõem para desenvolverem a produção, sendo que o acesso ao financiamento seguinte só é realizado mediante o pagamento do financiamento anterior.

O antigo PROCERA tratava-se de um crédito rural especial que atendia os assentados; sendo assim, pode-se observar o quanto os assentados rurais tinham satisfação ao se pronunciarem a favor deste antigo crédito rural, quando comparado ao PRONAF. Ao serem questionados sobre os dois financiamentos, foi possível extrair as seguintes informações: 


\begin{tabular}{ccc}
\hline & ASSENTADOS & \% \\
\hline Preferência pelo PROCERA & 18 & 90 \\
Preferência pelo PRONAF & 0 & 10 \\
Gostou tanto de um como do outro & 02 & $\mathbf{1 0 0}$ \\
\hline TOTAL & $\mathbf{2 0}$ & \\
\hline
\end{tabular}

Fonte: Pesquisa in loco Dorcelina Folador (Arapongas - PR.).

Período: 10/10/05 e 11/10/05.

Em sua maioria (90\%) relatou grande satisfação ao PROCERA. Para o restante $(10 \%)$ cada qual foi dado no seu tempo, sendo que o primeiro tratava da possibilidade do assentado concretizar o "sonho" de ter seu lote de terra, sua casa, suas primeiras ferramentas; já o PRONAF veio no período para possibilitarem os mesmos de produzirem a lavoura.

Vários depoimentos ilustram a satisfação pelo antigo PROCERA, os quais merecem destaque:

“... na época do PROCERA era bem melhor para nós”.

"Preferia o PROCERA, pois o tempo para pagar era maior".

“... o primeiro, pois terminei a casa”.

“... antes era específico para a reforma agrária”.

“... era melhor naquela época o dinheiro valia mais”.

“... PROCERA! Investimento que fica você vê no que gastou já PRONAF não”.

Há uma nítida preferência pelo fato de ter sido um financiamento específico criado para os assentados rurais; o grau de satisfação é tanto que quase todos se recordam das benfeitorias adquiridas naquele período. Já ao PRONAF há críticas sobre este financiamento, porém a maioria mantém em dia o seu pagamento. 


\section{CONSIDERAÇÕES FINAIS}

Em termos de políticas públicas o campo brasileiro ainda carece de mudanças significativas para o alcance de um desenvolvimento rural, este deve merecer atenção do atual governo para que as medidas postas em prática possam conciliar de fato crescimento econômico com desenvolvimento.

Os assentamentos rurais podem, quando bem estruturadas de recursos públicos; seja no investimento de suas propriedades, seja ao fornecimento de recursos para o custeio das lavouras, servir de aparato para que o crescimento econômico seja alcançado, pois assim como outras propriedades também possuem produções essenciais para toda a população brasileira.

Para os assentados infelizmente o PROCERA não existe mais, tendo de recorrer agora ao PRONAF, a insatisfação dos mesmos frente ao programa é fato, visto que antes havia um financiamento que lhes dava suporte de maneira particular.

Recorrer ao PRONAF é preciso, pois caso não o façam não terão condições econômicas para investirem e produzirem em suas propriedades. Por este motivo a maioria tenta estar em dia com as dívidas contraídas com o banco, pois sabem que caso estejam devendo ao mesmo não há como fazerem um novo financiamento.

Desde o PROCERA, se verifica que as políticas públicas não têm sido suficientes para atender aos assentados rurais, a exemplo do escasso recurso fornecido para a construção das casas no período em que os assentados chegaram ao Dorcelina Folador.

É preciso que se desenvolvam políticas públicas adequadas as suas realidades, pois assim como a maioria dos agricultores familiares, assentados não dispõem de meios suficientes para concorrem com um grupo pequeno residente no campo que possui um alto grau de integração com os setores agroindústrias. Muito pelo contrário, além de assentados não disporem desta integração, sofrem com dificuldades de comercialização de produtos.

Atrelado a isto, os recursos que lhes tem sido repassados pelo PRONAF, além de muitas vezes chegarem atrasados para a grande maioria do campo, aqui se inclui todos os agricultores familiares que dependem do financiamento; em muitos casos não lhes tem possibilitado extrair uma renda suficiente da lavoura. Pelo Dorcelina Folador, isto é claro e serve de 
exemplo, visto que no próprio local há assentados que vendem sua força de trabalho, seja em lavouras vizinhas ou mesmo nas proximidades.

O PRONAF tem em seu histórico mudanças que demonstram a preocupação do Estado em adequar o programa a realidade dos agricultores familiares. Sua criação e contínua adaptação vêm dando frutos significativos, pois mesmo em meio a inúmeras dificuldades tem possibilitado aos agricultores familiares, incluindo-se assentados rurais, sua permanência no campo.

\section{REFERÊNCIAS BIBLIOGRÁFICAS}

ALENTEJANO, Paulo Roberto R. O que há de novo no rural brasileiro?. : Terra Livre, n. ${ }^{\circ}$ 15, São Paulo, 2000, p. 87-112.

ESTEVA, Gustavo. Desenvolvimento. Dicionário do desenvolvimento: guia para o conhecimento como poder, Petrópolis, RJ: Vozes: p. 59- 83, 2000.

BRASIL, Ministério do desenvolvimento agrário secretaria da agricultura familiar. FAO. Disponível em: < www.mda.gov.br >. Acesso em: 05 dez. 2008.

BRASIL. Relatório de Gestão. PROCERA (Programa de Crédito Especial para a Reforma Agrária), Brasília: 2003.

FERREIRA, Brancolina et al. A agricultura familiar e o PRONAF: contexto e perspectivas. In: GASQUES, José Garcia; CONCEIÇÃO, Junia Cristina P. R. da (org.). Transformações da agricultura e políticas públicas. Brasil: IPEA, 2001, p. 480-537.

FRANCIS, Paula Chagas. O Programa nacional de fortalecimento da agricultura familiar (PRONAF): o estudo de caso do assentamento rural Dorcelina Folador (Arapongas PR). 2005. 148 f. Trabalho de conclusão de curso (Graduação em Geografia), Universidade Estadual de Londrina, Londrina.

GUANZIROLI, Carlos et al. Agricultura familiar e reforma agrária no século XXI. Rio de Janeiro: Garamond, 2001, p. 187 - 258.

HESPANHOL. O desenvolvimento do campo no Brasil. In: FERNANDES, B. M.; MARQUES, M. I. M.; SUZUKI, J. C. (orgs). Geografia agrária: teoria e poder. São Paulo: Expressão popular, p. 271- 287, 2007.

LEITE, Sérgio et al. Impactos dos assentamentos: um estudo sobre o meio rural brasileiro. São Paulo: Nead 6 Estudos/Unesp., 2004.

MDA, Ministério do Desenvolvimento Agrário. Marco referencial para apoio ao desenvolvimento de territórios rurais. Brasília, DF: Série documentos institucionais, 30 de maio, 2005. 
NEGRI, Paulo Sérgio. A identidade ecológica do Assentamento Dorcelina Folador Arapongas - PR. (Dissertação de mestrado). Departamento de Ciências Sociais, UEL. Londrina, 2005.

PROSCÊNCIO, Patrícia A. No descompasso da reforma agrária. União camponesa Tamarana. (monografia de conclusão de curso), Londrina: Departamento de Geociências, UEL, 1999.

(Recebido em dezembro/08. Aceito em abril/09) 